\title{
Individual placement and support: from research to practice
}

\author{
Miles Rinaldi, Rachel Perkins, Edmund Glynn, Tatiana \\ Montibeller, Mark Clenaghan \& Joan Rutherford
}

\begin{abstract}
Vocational rehabilitation for people with severe mental health problems is poorly developed in the UK. Although there is a clear evidence base indicating the effectiveness of approaches to helping people with severe mental health problems gain and retain employment there is generally a lack of awareness of this evidence. As a result there has been a lack of implementation within routine clinical practice of the most effective approaches to improving employment outcomes for such individuals.
\end{abstract}

'Occupation' and 'work' have long formed part of the care that people with mental health problems have received within mental health services in the UK (Birley, 2000). The reduction in the number of large psychiatric hospitals in favour of communitybased mental health services saw industrial therapy units move out of hospitals and into the community as sheltered work schemes. However, although their location moved into the community such schemes were not associated with the changes in practice or philosophy that benefitted community mental health services in general.

Sheltered work schemes do not provide a route to open employment (Martin, 1996; Reker \& Eikelmann, 1997; Whittington, 1997; Bond et al, 2001a). It was assumed that as people developed skills and confidence in a sheltered setting they would move on to open employment. However, despite good intentions, it seems that such schemes often succeed only in convincing individuals that they are capable of working only in a sheltered environment.

The World Health Organization (2000) has recommended that work be used as a way of reintegrating people with mental health problems into the community. As well as an income, work provides latent benefits such as social identity and status; social contacts and support; a means of structuring and occupying time, activity and involvement; and a sense of personal achievement. Unemployment is linked with increased general health problems, including premature death (Smith, 1985), and there is a strong relationship between unemployment and the development of mental health problems (Warr, 1987; Warner, 1994), including an increased risk of suicide (Lewis \& Sloggett, 1998). Three-quarters of people under 35 years of age with mental health problems who take their own lives are unemployed or on long-term sick leave when they do so (Appleby et al, 2006). Yet research shows that people with severe mental health problems who find paid employment experience not only increased income but also change in self-identity, improved quality of life and reduced symptoms (Arns \& Linney, 1993, 1995; Bond, 2001a; Fabian \& Wiedefeld, 1989; Fabian, 1992; Mueser et al, 1997; Van Dongen, 1996, 1998); these outcomes have not been found for people in sheltered work.

As community-based mental health services were being introduced in the UK, the nature of employment in the country was changing, with a decline in manufacturing and the growth of service industries. The emphasis on social inclusion and integration rather than segregation, as seen in the rise of social policy for people with mental health problems (Social Exclusion Unit, 2004; Prime Minister's Strategy Unit, 2006) and the changing expectations of these individuals themselves, have resulted in attempts to enable people with more severe mental health problems to gain and retain open employment through implementation of

All five authors work for the South West London and St George's Mental Health NHS Trust and are actively involved in the trust's individual placement and support programme. Miles Rinaldi is the trust's Vocational Services Manager (Vocational Services, Main Administration Building, Springfield University Hospital, 61 Glenburnie Road, London SW17 7DJ, UK. Email: Miles.Rinaldi@swlstgtr.nhs.uk). Rachel Perkins is the Director of Quality Assurance and User and Carer Experience, Edmund Glynn is Lead Employment Specialist for Kingston upon Thames, Tatiana Montibeller is Lead Employment Specialist for the London borough of Merton, Mark Clenaghan is Service Director for Merton and Joan Rutherford is Associate Medical Director and a consultant psychiatrist in Kingston upon Thames. 
evidence-based practice in vocational services (Department of Health, 2006).

\section{Employment rates}

People with mental health problems experience high levels of unemployment. The national Labour Force Survey for England in 2005 showed that 90\% of people with mental illness were unemployed, a figure that has not changed since 1998 (Labour Force Survey, 2005). Surveys conducted at a local level in the UK reveal similar rates of high unemployment (92\%: Perkins \& Rinaldi, 2002; 93\%: Marwaha et al, 2007). However, studies show that between $70 \%$ and $90 \%$ of people with mental health problems in the community want to gain or return to work (Rinaldi \& Hill, 2000; Secker et al, 2001). Furthermore, most people with mental health problems see the ability to return to work as a yardstick of recovery (Shepherd, 1989).

\section{Barriers to employment: low expectations}

People with mental health problems experience both individual and structural barriers to employment in the form of low motivation and confidence, side-effects of medication, fear of losing welfare benefits, employers' attitudes, perceived stigma and discrimination, and healthcare professionals' low expectations of them (Royal College of Psychiatrists, 2002; Rinaldi \& Perkins, 2004; Social Exclusion Unit, 2004).

The low expectations held by mental health professionals (Hugo, 2001; Burti \& Mosher, 2003; O'Brien et al, 2003; Marwaha \& Johnson, 2005; Lauber et al, 2006) are driven by the dominance of a model of illness that emphasises symptoms and cure as opposed to a model of recovery, accommodating disability, access and the social aspects of management (Boardman, 2003). Mental health professionals may underestimate the skills, experience and capabilities of their clients and overestimate the risk to employers. It is easy to see how low expectations can create a cycle of decreasing hope and opportunity that has a direct impact on people with mental health problems and employers (Fig. 1).

A survey in one London borough (Rinaldi \& Hill, 2000 ) found that $44 \%$ of people with mental health problems in paid employment had been advised by their mental health professionals not to work: supporting people to do the things they want to do is critical if we are to successfully enable recovery, independence and social inclusion.

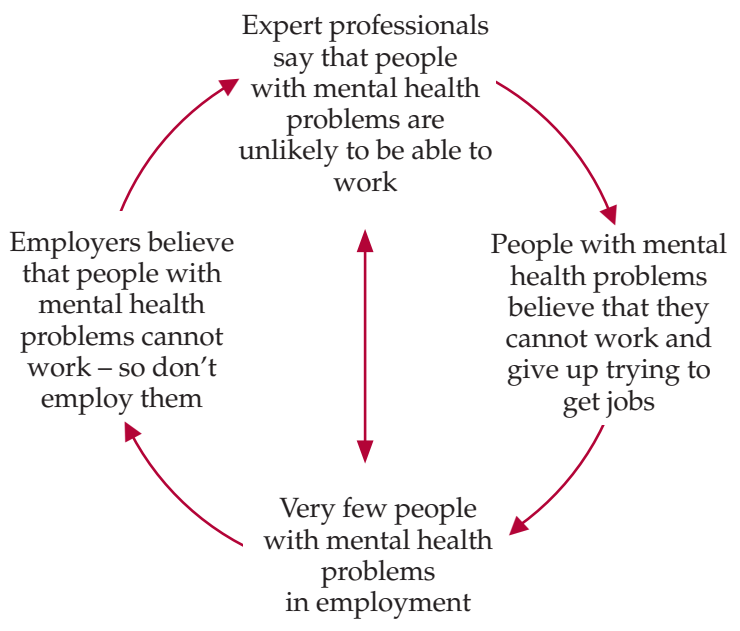

Fig. 1 Vicious cycle of low expectations (Rinaldi \& Perkins, 2005).

\section{Research evidence}

Research into vocational rehabilitation has followed two strands: investigations into client characteristics and who is 'employable', and studies of which models and approaches are most effective.

\section{Client factors: diagnosis is not important}

The majority of reviews show that there is little relationship between employment outcomes and the individual's diagnosis, severity of impairment and social skills (Bond et al, 2001a; MacDonaldWilson et al, 2001). The indicators that do appear to be robust predictors of work outcomes include recent employment history, motivation and self-efficacy. Wanting to work and believing that you can are the best predictors of work outcomes.

An ethnographic study of job-seeking among people with severe mental health problems (Alverson et al, 2006) revealed that, irrespective of the vocational rehabilitation intervention they were receiving, individuals fell into two categories: active job-seekers and passive job-seekers - active job-seekers did well vocationally whereas passive job-seekers made little or no progress. There is some initial evidence showing that it is possible to increase the motivation and/or self-efficacy in job-seeking behaviours of people with severe mental health problems through the use of cognitive-behavioural therapy (Gould et al, 2001; Lysaker et al, 2005; Lysaker et al, 2006), cognitive training (McGurk et al, 2005) and motivational interviewing (Debring et al, 2006; Larson et al, 2006). 


\section{Models and approaches}

The majority of randomised controlled trials (RCTs) to date have compared different forms of vocational rehabilitation such as prevocational training, group skills training and psychosocial rehabilitation. Macias et al (2006) reported a comparison between a PACT programme that attained high fidelity to the assertive community treatment (ACT) model with that of a more active approach to vocational rehabilitation, the clubhouse model; both services offered a supported employment. Overall, the PACT programme achieved a $64 \%$ employment rate, whereas the clubhouse achieved $47 \%$, although the difference was not statistically significant. The PACT programme was more effective at finding people jobs and in keeping them engaged with mental health services. The clubhouse was more effective at keeping people employed: individuals supported in open employment through the clubhouse remained in work on average 2 months longer and earned more than those supported by the PACT programme. However, PACT programmes require the employment specialist to provide clinical interventions (case management) in addition to vocational services.

A Cochrane review of vocational rehabilitation for people with severe mental illness found that individual placement and support (IPS) was more effective than other approaches in helping individuals to gain and retain competitive open employment (Crowther et al, 2001) (Box 2). Subsequent RCTS by Mueser et al (2004) and Cook et al (2005) published similar results in favour of the approach.

Individual placement and support (described in more detail below) has been most extensively used in the USA, where most of the RCTs reviewed by Crowther et al were conducted. However, the generalisability of the approach has now been

Box 2 Cochrane review of vocational rehabilitation for people with severe mental illness

- Eighteen randomised trials were identified

- The main finding was that supported employment was significantly more effective than prevocational training

- Clients in supported employment earned more and worked more hours than those in prevocational training

- There was no evidence that prevocational training was more effective than standard care in helping clients to obtain competitive employment

(Crowther et al, 2001) shown through effective implementation under RCT conditions in Canada (Latimer et al, 2006) and across Europe (Burns et al, 2007).

Several studies have shown that individual placement and support is more effective than day treatment (Bailey et al, 1998; Becker et al, 2001a; Drake et al, 1994, 19966), and RCTs have shown that it improves open employment outcomes more effectively than group skills training (Drake et al 1996a), sheltered workshops (Drake et al, 1999), and psychosocial rehabilitation based on prevocational training (Lehman et al, 2002; Mueser et al, 2004).

The longitudinal effectiveness of the approach has been shown in follow-up studies after 8-12 years (Salyers et al, 2004; Becker et al, 2007).

Typical cross-sectional rates of employment for people helped to gain and sustain open employment (paying at least the minimum wage) through individual placement and support average $30-40 \%$ in comparison with $10-12 \%$ for the other approaches studied (Crowther et al, 2001). People supported into open employment through this approach worked significantly more hours per month, had higher average earnings and had better job tenure (Drake et al, 1996a,b, 1999; Crowther et al, 2001; Mueser et al, 2004). In RCTs job tenure ranged from 2.5 to 8 months for a single job. In their evaluation of a 'real-world' programme, Lucca et al (2004) found that job tenure in a single job averaged 8.5 months for individuals receiving individual placement and support. The evidence shows that job tenure is increased when pre-employment job preferences are matched in the job obtained and where people report early satisfaction with the job (Xie et al, 1997; Mueser et al, 2001). In the majority of the RCTs individuals were in part-time employment, working $17.9-69 \mathrm{~h}$ per month (Crowther et al, 2001). A long-term follow-up study in the USA revealed that people preferred to work part-time because this was usually less demanding and it often allowed them to keep their social security and healthcare entitlements (Becker et al, 2007).

\section{The individual placement and support approach}

Individual placement and support (frequently abbreviated to IPS, and also known as evidence-based supported employment) is a variant of supported employment developed by Drake \& Becker. Its overriding philosophy is that anyone is capable of working competitively in the community if the right kind of job and work environment can be found and the right kind of support provided. Thus, the primary goal is not to change the individual, but to find a natural match between the individual's strengths and experiences and a job in the community. 
Supported employment programmes in mental healthcare help anyone who expresses the desire to work, regardless of the nature of their mental health problems. They encourage interest and build confidence in working, getting a job consistent with the individual's work goals and sustaining employment. Unlike traditional approaches to vocational rehabilitation, supported employment programmes do not undertake lengthy assessments or screen people for work readiness. People are not excluded because they are not 'ready' or because of prior work history, substance use or psychiatric symptoms. Unsurprisingly, there are individual differences in terms of work preferences, the nature of the support people want and whether or not they choose to disclose their mental health problem to an employer or work colleagues. Supported employment programmes respect these individual preferences, and tailor their interventions, including ongoing support, to the client's choices and ability.

Bond (2004) has identified seven principles of individual placement and support that are important in determining success in helping people to gain and retain employment, and has summarised the evidence that underpins them (Box 3 ).

\section{The employment specialist}

One of the key features of individual placement and support is that the employment specialist, who is the lead in implementing the intervention, is integrated into the community mental health team (CMHT). In practice, this means that the client also has access to psychiatrists, psychologists, nurses, social workers, occupational therapists and other care providers. Therefore all staff within the clinical team collaborate to provide optimal support to address the client's health and social care needs, including retaining or gaining employment and other vocational needs.

The employment specialist works directly with clients as part of the care planning process, addressing their vocational needs and ensuring that vocational goals are given a high priority. A key function for the employment specialist is to coordinate all vocational plans with other team members. Employment specialists work with up to 25 clients at any one time, engaging them on vocational issues, assessing their vocational needs, proactively helping them to gain and retain work or educational courses, providing welfare benefits advice and addressing their support needs, including adjustments to enable them to stay in work or education. Employment specialists spend $70 \%$ or more of their time in the community carrying out vocational engagement and assessment, job-finding and providing ongoing support to enable clients to sustain employment.
Box 3 Principles of individual placement and support

There is strong evidence that:

- services should be focused on competitive employment with a primary goal of integration into the general workforce

- eligibility should be based on the individual's preferences

- programmes should involve rapid job search and minimal prevocational training

There is moderately strong evidence that:

- vocational programmes should be integrated into the work of the clinical team

- attention to client preferences is important

- support should be available for an unlimited period, which should be tailored to the individual's needs

There is weak evidence from one study that:

- benefits counselling should be provided to help people claim all of the welfare benefits to which they are entitled

(Bond, 2004)

Employment specialists are not care coordinators, nor do they carry out care coordination tasks; they hold only vocational responsibilities but are fully integrated as equal members of the clinical team. In this regard, their role in individual placement and support differs form that of employment specialists in models such as PACT, who are also case managers. Sufficient training and ongoing supervision are critical to give employment specialists the skills to practise.

\section{Competencies and skills}

Employment specialists tend not to be mental health professionals by training: they are usually people who have skills and experience in vocational rehabilitation, human resources, marketing or occupational psychology and they may have personal experience of mental health problems. The key competencies for an employment specialist are listed in Box 4.

Obviously, employment specialists must develop good working relationships with other team members, but their key interactions will be with local employers, commercial employment agencies, government agencies such as Jobcentre Plus and Connexions, colleges and mainstream training providers, and also specialist independent employment and training services for people with mental health problems. 
Box 4 Key competencies for an employment specialist

- Experience and knowledge of job development, job marketing and job securing

- The ability to relate positively to employers

- Knowledge of mental health problems

- The ability to identify an individual's interests, strengths, skills, abilities and coping styles and to match them with jobs

- The ability to identify and arrange longterm support and reasonable adjustments to help people to keep jobs

- Knowledge about welfare benefits

- The ability to advocate for people with other team members, employers and families

\section{Fidelity}

In implementing individual placement and support, faithfulness to the model is important. The Evidencebased Supported Employment Fidelity Scale is a 15-item instrument assessing the fidelity of implementation of the critical ingredients of the approach (Bond et al, 1997). Programmes that score high on the scale are more effective than those with lower scores in assisting people with severe mental health problems to achieve open employment (Becker et al, 2001b; Drake et al, 2006; Bond, 2001b; 2007).

\section{Fictitious case example}

\section{Matthew}

Matthew, a 36-year-old with a diagnosis of schizophrenia, had a history of applying for jobs in a range of areas. His care coordinator felt that his psychiatric condition was too complex and its symptoms too severe for employment to be a realistic goal. On the occasions that Matthew did succeed in gaining a job he would soon become unwell and be dismissed. This reaffirmed the care coordinator's belief that employment was not good for Matthew's health. At a review of Matthew's care the psychiatrist referred him to the employment specialist in the team.

The employment specialist read Matthew's medical notes to gain an understanding of the particular issues before they met. Following a brief vocational assessment, Matthew, the employment specialist and the care coordinator together created a vocational plan. The employment specialist met frequently with Matthew and helped him to identify and apply for jobs that he wanted. After a short time, Matthew succeeded in gaining a part-time job working for a local newspaper, with ongoing support from the employment specialist.
When the care coordinator saw Matthew succeed in part-time work, she became more confident in his ability to sustain employment and she too was able to provide ongoing support to enable him to keep his job. Matthew has since moved from part-time work into a full-time position as an administrator in a retail company. He was helped to develop natural support networks with colleagues, friends and family, and he now receives less intensive support from the care coordinator and the employment specialist.

\section{Setting up a local individual placement and support service}

As mentioned above, individual placement and support has been used mostly in the USA, and it has been repeatedly shown that the transfer of complex mental health interventions from one culture to another cannot be assumed to carry the same benefits (Burns, 2000). There is now growing empirical evidence that the advantages of individual placement and support do translate to other countries, including European ones, but it is critical to understand how the trial results can be implemented in routine clinical practice without the involvement of the academic creators and in a context in which different social and welfare conditions prevail. In the next section we discuss the situation in the UK with reference to our own experience in setting up individual placement and support services within the South West London and St George's Mental Health NHS Trust.

\section{Need in the UK}

Standard 5 of the National Service Framework for mental health (Department of Health, 1999) requires that care plans for people with more serious mental health problems include 'action needed for employment, education or training or another occupation'. Evidence from one study suggests that CMHTs are still a considerable way from achieving this, with only $8 \%$ of case notes addressing vocational needs (Bertram \& Howard, 2006).

Both national and local surveys in the UK demonstrate the need for vocational services, but mental health professionals may not be aware of the clients who would like to find and retain employment. A national survey of mental health service clients in the UK found that $50 \%$ wanted help with finding paid work but were not receiving it (Healthcare Commission, 2006). Our own experience has shown that there is a need to work closely with psychiatrists, care coordinators, clients and carers to identify clients who might be interested in gaining employment. 
Box 5 Fears and concerns of care coordinators and psychiatrists

- Whether clients are able to work - not wanting to 'set them up to fail'

- The stress of working may lead to relapse and possibly hospitalisation

- Work would interfere with the client's mental stability

- Welfare benefits would be jeopardised

- Employers would discriminate against people with mental health problems

- Placing clients into positions of responsibility may increase risk of harm to others

- Employment specialists are not clinicians so they will not be able to judge whether someone is able to work

In setting up individual placement and support services, we have found that the mere presentation of research findings is not always the best way of changing approaches and practices. It is better to impart to the care team a practical understanding of the evidence base, in particular the evidence on client characteristics, the likely predictors of success and the need to encourage all clients to participate, regardless of their job readiness or problems such as substance misuse. It is important to work directly with care coordinators and psychiatrists to address their concerns (Box 5). There is, for example, no evidence that supported employment increases the likelihood of clinical deterioration, relapse or hospitalisation (Bond et al, 1995 , 2001a; Lehman, 1995; Drake et al, 1996a,b, 1999; Mueser et al, 2004; Burns et al, 2007).

It is recognised that people with mental health problems experience reduced self-esteem, selfefficacy and expectations of a successful outcome in job-seeking; indeed, they often have reduced motivation to seek work at all. There is a clear role for psychiatrists and care coordinators in reducing the negative psychological impact of unemployment, fostering clients' belief that they can work and providing the help and support they need to do so.

We found that some psychiatrists and care coordinators were already focused on enabling clients to gain and retain employment but lacked the local support, knowledge and time to link with local employers and mainstream educational providers.

\section{Team structure}

As an equal member of the team the employment specialist participates in all team meetings, including care programme approach (CPA) reviews, and has regular contact with the care coordinators, who also provide some employment support. An area with several CMHTs will usually have an employment specialist in each team and a programme manager; for an area with, say, four CHMTs and four employment specialists the programme manager is likely to be part-time. These five members of staff work as a unit but the individual working base of each of the employment specialists is their respective CMHT. Integrating vocational support into the CMHTs has a number of advantages (Box 6), including improved job retention (see 'Job retention' below).

In our experience, the early stages of integrating the role of employment specialist into a CMHT requires the programme manager's support, but it is the CMHT manager who will settle the individual, a non-clinician, into the team. We have found that employment specialists sometimes feel lost and out of their depth in team meetings and are fearful of saying the wrong thing. The team manager has a key role to play in ensuring that the employment specialist is given the opportunity to discuss vocational issues, that the respective expertise of the different disciplines is heard, that the employment specialist is valued as an equal member of the team and that vocational issues are accorded the same level of importance as other clinical issues.

In the implementation of an individual placement and support programme in our own trust, we followed the trust's single management policy. In practice this has meant that the employment specialist is directly responsible to the CMHT manager and receives professional supervision from the programme manager, who ensures that the individual is working in line with evidence-based practice and with high fidelity to the model, and oversees development of their job-related skills and knowledge.

Moving an intervention from research to routine clinical practice can present challenges. One of the principles of individual placement and support is

\section{Box 6 Integrated $v$. non-integrated vocational} services

Integrated vocational services consistently offer four advantages over non-integrated:

- more effective engagement and retention

- better communication

- opportunities for clinicians to understand and focus on employment

- incorporation of clinical information into vocational plans and services

(Drake et al, 2003) 
ongoing time-unlimited support. In our practice, once a client has moved into open employment and settled into work this support is provided by the care coordinator and, where possible, through the use of natural supports (colleagues, family, friends) in the community. If the client subsequently experiences problems at work and needs the help of the employment specialist they can return to the specialist's case-load. We have found that this enables a flow of people off the employment specialist's caseload, creating space for new referrals of clients who need vocational support while maintaining the case-load at 25.

\section{Management and leadership}

If culture and practice are to be changed to incorporate individual placement and support, then vocational issues must become part of the core business of the trust as a whole. They must form part of its core organisational processes, from frontline teams through to the board of directors.

In our case, funding for employment specialists came from the significant downsizing of a sheltered workshop and the closure of a day centre. We have heard team members asking why funding (irrespective of its origin or the commissioning intention) has been spent on an employment specialist rather than on more care coordinators for their team. Integrating an employment specialist into a team is not as simple as increasing the team's skills mix. Both clinical leadership and team management can help team members to reconnect with the communal goal of meeting clients' multiple needs and can help to push team members beyond professional barriers in the direction of improved team functioning (Firth-Cozens, 2001; Royal College of Psychiatrists, 2001).

Evidence shows that where mental health services have successfully implemented an innovative practice they have usually had at least one individual who champions the innovation (Backer et al, 1986). Mental health trusts that have created the role of a vocational services manager with responsibility and sufficient authority to implement change have produced more effective vocational outcomes for people with severe mental health problems (Department of Health, 2006). When introducing supported employment, the 'champion' identifies respected frontline mental health professionals who can help lead the implementation effort. These in turn recruit other staff to join in the planning and development of the new programme, so that all staff feel ownership of it (Bond et al, 2001b).

It can be tempting when creating the roles of employment specialist and vocational services manager simply to alter existing job specifications to accommodate these roles. It is essential to consider the competencies and skills required for such posts and to question whether clinicians really are the best people for such jobs. Employment specialists must believe that people with severe mental health problems can work if the right job is found and the right supports are put into place. Their role is to support the client in their efforts, not to decide whether the client should or could work.

\section{Job retention}

Most research on individual placement and support has focused on enabling people to gain jobs once they have lost them. However, it is equally, if not more, important to prevent people from losing their jobs in the first place (Royal College of Psychiatrists, 2002). People with mental health problems are at more than double the risk of losing their jobs than those without such difficulties (Burchardt, 2003), and those with severe mental health problems are even more likely to become unemployed (Perkins \& Rinaldi, 2002).

The CMHTs in our trust have found it important to support clients who have a doctor's medical certificate (sick note) exempting them from work or who are at risk of losing their jobs owing to mental health issues. As a result the employment specialists have focused on both job reintegration and retention.

\section{Supported education}

Some supported employment services in the USA also offer supported education to enable people with severe mental health problems to access, participate and succeed in post-secondary education or training (Mowbray et al, 2003). The same evidence-based principles as set out in Box 4 apply, but focused on mainstream education.

We followed this practice in the individual placement and support service in our trust, as clients identified mainstream education as a desirable outcome. We found that care coordinators already had good experience of supporting clients embarking on some form of education, and often provided ongoing support once they had moved into education. The additional provision of supported education allows clients to establish a career ladder through gaining new skills. We have observed that some clients have gained employment and after a period of time have moved on to take up mainstream education. This has allowed them to experience the working environment and then gain educational skills and qualifications to progress to their next job. 


\section{Resistance and problems}

Internal

Setting up a new, innovative service may generate major resistance among staff. Clinical team members typically place varying degrees of emphasis on the 'biological', 'psychological' and 'social' aetiologies of mental health and ill health (Hannigan, 1999) and we have found that it has been important to work with all team members both directly and indirectly. Although a certain amount can be achieved by the vocational services manager and the employment specialists in changing opinions and attitudes both within and outside the CMHT, it is equally important that the team's psychiatrists and care coordinators, who see the positive influence that helping people to return to work can have, teach colleagues from their respective professions about both the clinical and individual benefits to clients.

Some mental health professionals have been sceptical about the principle of rapid job search and the effects it might have on clients. We have been able to overcome this concern by explaining that the programme works in an individualised way, respecting client's preferences and choice and that rapid job search does not necessarily mean that clients move rapidly into jobs. It has also been important to voice feedback from clients who prefer to move directly towards employment instead of going through transitional preparatory activities.

In addition, we have found that psychiatrists and care coordinators are more likely to believe that approaches work if they can see them with their own eyes in their own teams. Consequently, it has been important to demonstrate through clear monitoring that clients have been able to gain and retain employment. This has served to convert sceptical care coordinators and psychiatrists to the belief that clients can gain and retain employment without relapse or hospitalisation, even those who have a diagnosis of psychosis. This in turn has increased demand for the service not only from psychiatrists and care coordinators but also directly from clients.

\section{Clients and carers}

Users and carers have questioned who is benefiting from our individual placement and support service, concerned that it is targeting not clients with the most complex health and social care needs but those with mild to moderate mental health problems. Again, it has been important to demonstrate through clear monitoring what proportion of our clients are on the enhanced level of care planning (enhanced CPA) and have more severe illnesses such as schizophrenia.

Although individual placement and support has increased services and choice within our trust, some clients and carers have found the transition from traditional building-based services to community outreach services difficult. While acknowledging the positive benefits of these new services, they have mourned the loss of the more traditional units.

Partnership working

Working in partnership with other statutory, community and voluntary sector agencies has been critical. Employment agencies such as Jobcentre Plus and Connexions and mainstream education and training providers have often needed information, advice and guidance in working with people with severe mental health problems. Through a capacitybuilding approach this has led to greater awareness of how to engage and work with people with severe mental health problems; it has also resulted in successful partnership working to secure additional vocational resources for people with severe mental health problems.

\section{Employers}

Discrimination by employers is seen by all as a barrier to enabling people with mental health problems gain and retain employment. One way of challenging such attitudes is to recognise that, when working with employers, taking an illness or medicalised approach as a way of reducing discrimination has the reverse effect, actually increasing it (Sayce, 2000). General mental health awareness training inevitably involves describing diagnoses and problems rather than individuals. Employers do not recruit 'schizophrenia' any more than they do 'heart disease': they employ an individual who has the skills, abilities and experience for the job.

We have found that taking an individualised approach focusing on a person's skills, abilities and potential workplace adjustments rather than their health status and deficits enables us to work well with employers. In addition to educating employers, it has also been important to offer them ongoing support.

\section{Evaluation}

We established individual placement and support in eight CMHTs at different times, as funding became available. Integration of employment specialists into the CMHTs resulted in significant increases in the number and proportion of clients engaged in open employment or educational activity between baseline and 6 months and between 6 and 12 months. The employment specialists were supporting 38\% in open employment at 6 months and $39 \%$ at 12 months, with a job retention rate of $88 \%$ (Rinaldi \& Perkins, 2007). These outcomes are in line with 
those achieved in randomised controlled trials of individual placement and support in the USA (e.g. Drake et al, 1996a,b; Mueser et al, 2004). These results suggest that individual placement and support can be effective in the UK as well as in the USA, and within routine clinical practice as well as in research trials.

We have also implemented individual placement and support within an early intervention service for people with first-episode psychosis (Rinaldi et al, 2004). In this younger group we found that education is as important as open employment. At the start 38\% of the clients were in open employment $(13 \%)$ or mainstream education, but by 6 months this has risen to $69 \%$ (35\% in open employment), by 12 months to $72 \%$ (44\% in open employment) and by 18 months to $81 \%$ ( $48 \%$ in open employment), (further details available from the author on request).

Supported employment programmes for people with severe mental health problems have sometimes been criticised for only helping people to get poorly paid, entry-level jobs. The research literature from the USA tends to support such a belief. However, our clients gained and/or retained jobs across all the standard occupation classification groups. In addition, clients with schizophrenia, who are often considered to be the most disadvantaged in relation to employment, were successfully supported to gain employment in more senior positions, as accountants, IT workers, hairdressers, carpenters, bookmakers and drivers, as well as hotel workers and shop assistants (Rinaldi et al, 2006).

\section{Conclusions}

Individual placement and support is an evidencebased practice that has been shown to be more effective than other approaches in helping people with severe mental health problems gain and sustain employment. Research clearly demonstrates that it is the support provided to clients that most affects vocational outcomes. Reviews of the research literature repeatedly demonstrate little relationship between employment outcomes and diagnosis, severity of impairment and social skills. There is increasing evidence that the individual placement and support model can be generalised beyond the USA to the UK, indeed to other European countries, and beyond the clinical trial to routine clinical practice.

\section{References}

Alverson, H., Carpenter, E. \& Drake, R. E. (2006) An ethnographic study of job seeking among people with severe mental illness. Psychiatric Rehabilitation Journal, 30, 15-22.

Appleby, L., Shaw, J., Kapur, N., et al (2006) Avoidable Deaths: Five Year Report by the National Confidential Inquiry into Suicide and
Homicide By People with Mental Illness. University of Manchester. http:/ /www.medicine.manchester.ac.uk/suicideprevention/ nci/

Arns, P. G. \& Linney, J. (1993) Work, self, and life satisfaction for persons with severe and persistent mental disorders. Psychosocial Rehabilitation Journal, 17, 63.

Arns, P. G. \& Linney, J. A. (1995) Relating functional skills of severely mentally ill clients to subjective and societal benefits. Psychiatric Services, 46, 260.

Backer, T., Liberman, R. \& Kuehnel, T. (1986) Dissemination and adoption of innovative psychosocial interventions. Journal of Consulting and Clinical Psychology, 54, 111-118.

Bailey, E. L., Ricketts, S. K., Becker, D. R., et al (1998) Do long-term day treatment clients benefit from supported employment? Psychiatric Rehabilitation Journal, 22, 24-29.

Becker, D. R., Bond, G. R., McCarthy, D., et al (2001a) Converting day treatment centers to supported employment programs in Rhode Island. Psychiatric Services, 52, 351-357.

Becker, D. R., Smith, J., Tanzman, B., et al (2001b) Fidelity of supported employment programs and employment outcomes. Psychiatric Services, 52, 834-836.

Becker, D. R., Whitley, R., Bailey, E. L., et al (2007) Long term employment trajectories amongst participants with severe mental illness in supported employment. Psychiatric Services, 58, 922-928.

Bertram, M. \& Howard, L. (2006) Employment status and occupational care planning for people using mental health services. Psychiatric Bulletin, 30, 48-51.

Birley, J. (2000) An historic perspective on psychiatric rehabilitation. Rehab Good Practice Network Newsletter, (1). UK Health Advisory Service.

Boardman, J. (2003) Work, employment and psychiatric disability. Advances in Psychiatric Treatment, 9, 327-334.

Bond, G. (2004) Supported employment: evidence for an evidence-based practice. Psychiatric Rehabilitation Journal, 27, 345-359.

Bond, G. R. (2007) Modest implementation efforts, modest fidelity, and modest outcomes. Psychiatric Services, 58, 334.

Bond, G. R., Dietzen, L. L., McGrew, J. H., et al (1995) Accelerating entry into supported employment for persons with severe psychiatric disabilities. Rehabilitation Psychology, 40, 91-111.

Bond, G. R., Becker, D. R., Drake, R. E., et al (1997) A fidelity scale for the individual placement and support model of supported employment. Rehabilitation Counselling Bulletin, 40, 265-284.

Bond, G. R., Resnick, S. G., Drake, R. E., et al (2001a) Does competitive employment improve non-vocational outcomes for people with severe mental illness? Journal of Consulting and Clinical Psychology, 69, 489-501.

Bond, G. R., Becker, D. R., Drake, R. E., et al (2001b) Implementing supported employment as an evidence-based practice. Psychiatric Services, 52, 313-322.

Burchardt, T. (2003) Employment Retention and the Onset of Sickness or Disability. Evidence from the Labour Force Survey Longitudinal Datasets (In-house Report 109). UK Department for Work and Pensions.

Burns, T. (2000) Models of community treatments in schizophrenia: do they travel? Acta Psychiatrica Scandinavica, 102, 11-14.

Burns, T., Catty, J., Becker, T. et al (2007) The effectiveness of supported employment for people with severe mental illness: a randomised controlled trial. Lancet, 370, 1146-1152.

Burti, L. \& Mosher L. R. (2003) Attitudes, values and beliefs of mental health workers. Epidemiologia e Psichiatria Sociale, 12, 227-231.

Cook, J. A. Leff, H. S., Blyler, C. R., et al (2005) Results of a multisite randomized trial of supported employment interventions for individuals with severe mental illness. Archives of General Psychiatry, 62, 505-512.

Crowther, R., Marshall, M., Bond, G., et al (2001) Vocational rehabilitation for people with severe mental illness. Cochrane Database of Systematic Reviews, issue 3. Update Software.

Department of Health (1999) National Service Framework for Mental Health. UK Department of Health.

Department of Health (2006) Vocational Services for People with Severe Mental Health Problems: Commissioning Guidance. UK Department of Health. 
Drake, R. E., Becker, D. R., Biesanz, J. C., et al (1994) Rehabilitative day treatment vs. supported employment: I. Vocational outcomes. Community Mental Health Journal, 30, 519.

Drake, R. E., McHugo, G. J., Becker, D. R., et al (1996a) The New Hampshire Study of Supported Employment for People with Severe Mental Illness. Journal of Consulting and Clinical Psychology, 64, 391-399.

Drake, R. E., Becker, D. R., Biesanz, B. A., et al (1996b) Day treatment versus supported employment for persons with severe mental illness. A replication study. Psychiatric Services, 47, 1125-1127.

Drake, R. E., McHugo, G. J., Bebout, R. R., et al (1999) Arandomized clinical trial of supported employment for inner-city patients with severe mental disorders. Archives of General Psychiatry, 56, 627-633.

Drake, R. E., Becker, D. R., Bond, G. R., et al (2003) A process analysis of integrated and non-integrated approaches to supported employment. Journal of Vocational Rehabilitation 18, 51-58.

Drake, R. E., Bond, G. R. \& Rapp, C. (2006) Explaining the variance within supported employment programs. Comment on 'what predicts supported employment outcomes?' Community Mental Health Journal, 42, 315-318.

Drebing, C. E., Hebert, M., Mueller, L. N., et al (2006) Vocational rehabilitation from a behavioral economics perspective. Psychological Services, 3, 181-194.

Fabian, E. S. (1992) Supported employment and the quality of life: does a job make a difference? Rehabilitation Counselling Journal, 36, 84

Fabian E. S. \& Wiedefeld, M. F. (1989) Supported employment for severely psychiatrically disabled persons: a descriptive study. Psychosocial Rehabilitation Journal, 13, 53-60.

Firth-Cozens, J. (2001) Multidisciplinary teamwork. The good, bad, and everything in between. Quality in Health Care, 10 $65-66$

Gould, R. A., Mueser, K. T., Bolton, E., et al (2001) Cognitive therapy for psychosis in schizophrenia. A preliminary metaanalysis. Schizophrenia Research, 48, 335-342.

Hannigan, B. (1999) Joint working in community mental health: prospects and challenges. Health and Social Care in the Community, 7, 25-31.

Healthcare Commission (2006) Survey of Users 2006 - Mental Health Services. UK Healthcare Commission.

Hugo, M. (2001) Mental health professionals' attitudes towards people who have experienced a mental health disorder. Journal of Psychiatric and Mental Health Nursing, 8, 419-425.

Labour Force Survey (2005) Labour Force Survey. UK Office for National Statistics.

Larson, J. E., Barr, L. W., Corrigan, P. W., et al (2006) Perspectives on benefits and costs of work from individuals with psychiatric disabilities. Journal of Vocational Rehabilitation, 26, 71-77.

Latimer, E. A., Lecomte, T., Becker, D. R., et al (2006) Generalisability of the individual placement and support model of supported employment: results of a Canadian randomised controlled trial. British Journal of Psychiatry, 189, 65-73.

Lauber, C., Nordt, C., Braunschweig, C., et al (2006) Do mental health professionals stigmatize their patients? Acta Psychiatrica Scandinavica, 113, 51-59.

Lehman, A. F. (1995) Vocational rehabilitation in schizophrenia. Schizophrenia Bulletin, 28, 8-15.

Lehman, A. F., Goldberg, R., Dixon, L. B., et al (2002) Improving employment outcomes for persons with severe mental illnesses. Archives of General Psychiatry, 59, 165-172.

Lewis, G. \& Sloggett, A. (1998) Suicide, deprivation and unemployment. Record linkage study. BMJ, 317, 1283-1286.

Lucca, A. M., Henry, A. D., Banks, S., et al (2004) Evaluation of an Individual Placement and Support model (IPS) program. Psychiatric Rehabilitation Journal, 27, 251-257.

Lysaker, P. H., Bond, G. R., Davis, L. W., et al (2005) Enhanced cognitive-behavioral therapy for vocational rehabilitation in schizophrenia. Effects on hope and work. Journal of Rehabilitation Research and Development, 42, 673-682.

Lysaker, P. H., Davis, L. W. \& Beattie, N. (2006) Effects of cognitive behavioral therapy and vocational rehabilitation on metacognition and coping in schizophrenia. Journal of Contemporary Psychotherapy, 36, 25-30.
MacDonald-Wilson, K. L., Rogers, E. S. \& Anthony, W. A. (2001) Unique issues in assessing work function among individuals with psychiatric disabilities. Journal of Occupational Rehabilitation, 11, 217-232.

Macias, C., Rodican, M. S. W., Hargreaves, W. A., et al (2006) Supported employment outcomes of a randomised controlled trial of ACT and clubhouse models. Psychiatric Services, 57, 1406-1415.

Martin, M. J. (1996) Employment rehabilitation schemes for people with mental health problems. Health and Social Care in the Community, 4, 271-279.

Marwaha, S. \& Johnson, S. (2005) Views and experiences of employment among people with psychosis: a qualitative descriptive study. International Journal of Social Psychiatry, 51, 302-316.

Marwaha, S., Johnson, S., Bebbington, P., et al (2007) Rates and correlates of employment in people with schizophrenia in the UK, France and Germany. British Journal of Psychiatry, 191, 30-37.

McGurk, S. R., Mueser, K. T. \& Pascaris, A. (2005) Cognitive training and supported employment for persons with severe mental illness: one-year results from a randomized controlled trial. Schizophrenia Bulletin, 31, 898-909.

Mowbray, C. T., Gutierrez, L. M., Bellamy, C. D., et al (2003) Replication of a psychosocial rehabilitation program: a case study analysis of supported education. Journal of Community Psychology, 31, 437-458.

Mueser, K. T., Becker, D. R., Torrey, W. C., et al (1997) Work and nonvocational domains of functioning in persons with severe mental illness: a longitudinal analysis. Journal of Nervous and Mental Disease, 185, 419-426.

Mueser, K. T., Becker, D. R. \& Wolfe, R. (2001) Supported employment, job preferences, job tenure and satisfaction. Journal of Mental Health, 10, 411-417.

Mueser, K. T., Clark, R. E., Haines, M., et al (2004) The Hartford Study of Supported Employment for persons with severe mental illness. Journal of Consulting and Clinical Psychology, 72, 479-490.

O'Brien, A., Price, C., Burns, T., et al (2003) Improving the vocational status of patients with long-term mental illness: a randomised controlled trial of staff training. Community Mental Health Journal, 39, 333-347.

Perkins, R. \& Rinaldi, M. (2002) Unemployment rates among patients with long-term mental health problems. A decade of rising unemployment. Psychiatric Bulletin, 26, 295-298.

Prime Minister's Strategy Unit (2006) Reaching Out: An Action Plan for Social Exclusion. UK Cabinet Office.

Reker, T. \& Eikelmann, B. (1997) Work therapy for schizophrenic patients. Results of a 3-year prospective study in Germany. European Archives of Psychiatry and Clinical Neuroscience, 247, 314-319.

Rinaldi, M. \& Hill, R. (2000) Insufficient Concern: The Experiences, Attitudes and Perceptions of Disabled People and Employers towards Open Employment in one London Borough. Merton MIND.

Rinaldi, M. \& Perkins, R. (2004) Vocational rehabilitation. Psychiatry, 3, 54-56.

Rinaldi, M. \& Perkins, R. (2005) Early intervention: a hand up the slippery slope. In New Thinking about Mental Health and Employment (eds B. Grove, J. Secker \& P. Seebohm). Radcliffe Press.

Rinaldi, M. \& Perkins, R. (2007) Implementing evidence-based supported employment. Psychiatric Bulletin, 31, 244-249.

Rinaldi, M., McNeil, K. M., Firn, M., et al (2004) What are the benefits of evidence-based supported employment for patients with first-episode psychosis? Psychiatric Bulletin, 28, 281-284.

Rinaldi, M., Perkins, R., Hardisty, J., et al (2006) Not just stacking shelves. A Life in the Day, 10, 8-14.

Royal College of Psychiatrists (2001) Consultants as Partners in Care: The Roles and Responsibilities of Consultant Psychiatrists in the Planning and Provision of Mental Health Services for People with Severe Mental Illness (Council Report CR96). Royal College of Psychiatrists.

Royal College of Psychiatrists (2002) Employment Opportunities and Psychiatric Disability (Council Report CR111). Royal College of Psychiatrists. 
Salyers, M. P., Becker, D. R., Drake, R. E., et al (2004) A ten-year follow-up of a supported employment program. Psychiatric Services, 55, 302.

Sayce, L. (2000) From Psychiatric Patient to Citizen: Overcoming Discrimination and Social Exclusion. MacMillan.

Secker, J., Grove, B. \& Seebohm, P. (2001) Challenging barriers to employment, training and education for mental health clients. The client's perspective. Journal of Mental Health, 10, 395-404.

Shepherd, G. (1989) The value of work in the 1980s. Psychiatric Bulletin, 13, 231-233.

Smith, R. (1985) 'Bitterness, shame, emptiness, waste'. An introduction to unemployment and health. BMJ, 291, 1024-1028.

Social Exclusion Unit (2004) Mental Health and Social Exclusion Report. UK Office of the Deputy Prime Minister.

Van Dongen, C. J. (1996) Quality of life and self-esteem in working and nonworking persons with mental illness. Community Mental Health Journal, 32, 535-548.

Van Dongen, C. J. (1998) Self-esteem among persons with severe mental illness. Issues in Mental Health Nursing, 19, 29-40.

Warner, R. (1994) Recovery from Schizophrenia: Psychiatry and Political Economy (2nd edn). Oxford University Press.

Warr, P. (1987) Unemployment and Mental Health. Oxford University Press.

Whittington, D. (1997) The Effectiveness of the Industrial Therapy Organisation: The Executive Report on a Three Year Study. University of Ulster.

World Health Organization (2000) Mental Health and Work: Impact, Issues and Good Practices. World Health Organization.

Xie, H., Dain, B. J., Becker, D. R., et al (1997) Job tenure among persons with severe mental illness. Rehabilitation Counselling Bulletin, 40, 230-239.

\section{MCQs}

1 Vocational rehabilitation:

a is a new concept

b has never been part of mental health services

c has historically been part of mental health services

d is not applicable to people with severe mental health problems

e is not a concept that psychiatrists need to consider.

2 In the employment arena:

a level of disability determine their success in gaining employment

b diagnosis is key to whether a client will be able to return to work

c motivation and self-efficacy are the most important characteristics of whether a client will be able to return to work

d severity of impairment is key to whether a client will be able to return to work

e social skills are key to whether a client will be able to return to work.
3 As regards approaches to helping people to return to work:

a supported employment is a new form of sheltered workshop

$\mathrm{b}$ prevocational training is more effective than supported employment in helping people obtain open employment

c supported employment is most successful when integrated with mental health teams

$\mathrm{d}$ there is little research evidence indicating the most effective approaches to helping people gain open employment

e people with severe mental health problems cannot benefit from vocational rehabilitation.

4 Supported employment programmes in mental health services:

a help any client who expresses the desire to work

b undertake lengthy assessments

c screen people for work readiness

d increase the likelihood of relapse or hospitalisation

e do not work with people with a history of substance misuse.

5 Research on supported employment:

a has been conducted only in the USA

b has been conducted across Europe

c has not been subject to a systematic review

$\mathrm{d}$ has not been applied in routine clinical practice in England

e has not been shown to be effective for people with severe mental health problems.

\begin{tabular}{|lllllll|}
\hline \multicolumn{2}{|l}{ MCQ answers } & & & & & \\
1 & & 2 & & & & \\
a F & a F & a F & a T & a F \\
b F & b F & b F & b F & b T \\
c T & c T & c T & c F & c F \\
d F & d F & d F & d F & d F \\
e F & e F & e F & e F & e F \\
\end{tabular}

